\title{
Air drag coefficient of textile-covered elastic cylinders - preliminary aerodynamic studies
}

\author{
Jana Siegmund ${ }^{1}$, Ellen Wendt ${ }^{1}$, Stefan Rothe ${ }^{1}$, Yordan Kyosev ${ }^{1 *}$, Veit Hildebrand ${ }^{2}$, Harald \\ Pfifer $^{2}$, Sebastian Schubert ${ }^{2}$, Stefan Schleifenbaum ${ }^{3}$ \\ ${ }^{1}$ Chair of Development and Assembly of Textile Products, Institut für Textilmaschinen und Textile \\ Hochleistungswerkstofftechnik (ITM), Technische Universität Dresden, Dresden, Germany \\ ${ }^{2}$ Chair of Flight Mechanics and Control, TU Dresden, Dresden, Germany \\ ${ }^{3}$ ZESBO - Center for Research on Musculoskeletal Systems, Klinik und Poliklinik für Unfall-, Wiederherstellungs- \\ und Plastische Chirurgie, University of Leipzig, Leipzig, Germany \\ *Corresponding author E-mail address: yordan.kyosev@tu-dresden.de
}

\section{INFO}

CDAPT, ISSN 2701-939X

Peer reviewed article

2021, Vol. 2, No. 2, pp. 187-195

DOI 10.25367/cdatp.2021.2.p187-195

Received: 10 November 2021

Accepted: 10 December 2021

Available online: 16 December 2021

\begin{abstract}
This paper presents preliminary experimental results on the influence on the aerodynamic drag of a cylinder from the cylinder type (i.e., rigid or soft) and its textile surface. Both a rigid cylinder and a soft-body cylinder, with a gelatin layer, each with five different textile surfaces were measured in the wind tunnel using force measurement technology. The drag coefficient was determined for several Reynolds numbers. The study shows that the elasticity of a cylinder has a significant influence on the drag force and the airflow type. However, the influence of the soft-body cylinder depends on the respective fabric. With the given measurements, no exact statements can yet be made to quantify the influence. This influence must be studied independently and in conjunction with the textile surface in order to gain understanding of the overall system of airflow, textile and elastic body.
\end{abstract}

Keywords

air-drag coefficient,

soft body,

textile cover,

aerodynamic study,

elasticity

(C) 2021 The authors. Published by CDAPT.

This is an open access article under the CC BY-NC-ND license

https://creativecommons.org/licenses/ peer-review under responsibility of the scientific committee of the CDAPT.

(C) 2021 CDAPT. All rights reserved.

\section{Introduction}

In several sports, rescue and other activities, people stay and interact in a windy environment at different speeds. The air resistance of "everyday" clothed people pursuing their hobbies is generally not overly important. For high-performance athletes, e.g. cyclists in a competitive environment, this is a decisive factor influencing their performance. Equally important is the interaction of airflow, the clothing and the human body in sports such as bodyflying and wingsuit flying. Current studies of air resistance of bodies 
and textiles are conducted on rigid models of the human body and do not take into account the elasticity of the body as it interacts with the airflow [1], [2], 3]. Further studies show that modified surfaces can influence the resistance by changing the structure or by deformation by means of coatings or stretched films [4]. This suggests that the deformation of soft tissue and skin and their oscillations during movement can significantly change the drag of the overall system. This interaction can affect an athlete's performance and/or cause difficulty in controlling their movements.

In this paper, preliminary studies on the influence of the elastic human body interacting with the airflow are presented. An overview of the state of the art is followed by a brief description of the test equipment and the used materials. A rigid metallic cylinder and a soft gelatin cylinder are compared by means of force measurement and the determination of the drag coefficient. Furthermore, these cylinders are covered with fabric and the influence on the measured values is investigated. Preliminary results show that the deformability of the human body can significantly affect the drag coefficient of textiles in some Reynolds number ranges.

\section{State of the art}

Studies on the drag of cylindrical bodies have been carried out so far on cylinders with non-moving and rigid, non-deformable surfaces [1], [2], [3], using experimental or numerical methods. The same equipment is used to study the change in resistance with different surface structures [4]. The active reduction of the drag of morphological cylinders was considered in a wind tunnel [5]. Here, the experimental specimens consisted of a rigid spoke framework with axial cavities covered with a stretched elastomeric film. The study of the influence of flexible surfaces on drag or propulsion was carried out in the context of biomechanical motion effects of various living beings [6]. In such experiments, the dimensionless drag coefficient is studied as a function of the Reynolds number $\operatorname{Re}=\rho$ $u L / \mu$, where $\rho$ is the density of the fluid, $u$ is the flow velocity, $L$ is the characteristic length dimension, and $\mu$ is the dynamic viscosity of the fluid. At low Reynolds numbers, which are common for low flow velocities and smaller characteristic dimensions, the drag coefficients $C_{D}$ usually remain almost constant (Fig. 1). Near the critical value of the Reynolds number, the fluid motion in the boundary layer changes from laminar to turbulent, with a significantly lower drag coefficient. As the Reynolds number increases into the transcritical region, the drag coefficients increase to a relatively stable value that lies between the initial and the critical values.

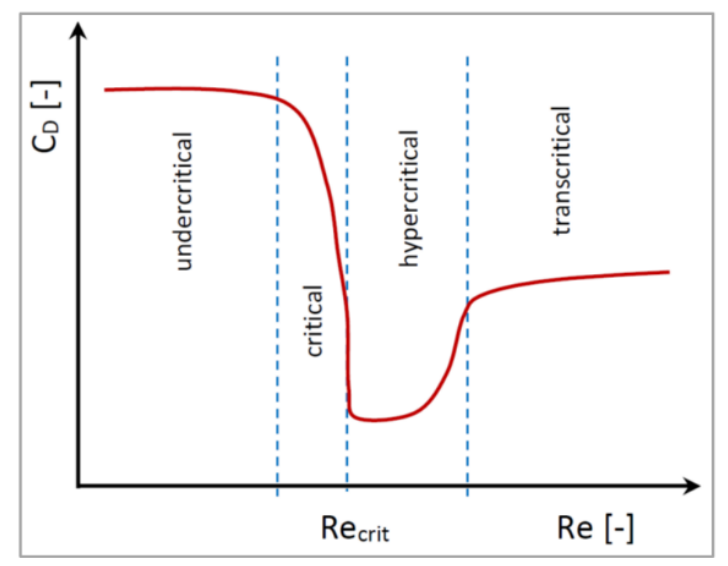

Fig. 1 Characterization of different areas of the resistance, following [6].

Textile clothing changes the boundary layer between the body and the fluid and influences the drag coefficient. Figure 2 shows the drag force for rigid cylinders covered with different textile structures as a function of the Reynolds number. These curves have been measured in the wind tunnel of the TU 
Dresden in recent years. The diagram shows that the textile surface has a significant influence on the drag coefficient and can transform the fluid motion from one state to another (laminar, critical and turbulent). Recall that all these studies have been conducted on rigid bodies. However, the human body is not rigid; it consists of deformable soft tissue. The authors found no direct work in the literature on the drag coefficient of clothed deformable bodies. Viewed from the perspective of textiles, the drag coefficient of yarns is studied in several works, since it is important for the optimization of ring spinning and for air-jet weaving processes [7]. For cotton and wool yarns [8], which have been investigated as single yarns in the balloon of the ring spinning process, it is known that yarn hairiness increases air resistance by about $25-30 \%$. The drag force is also important for the spunbond process [9].

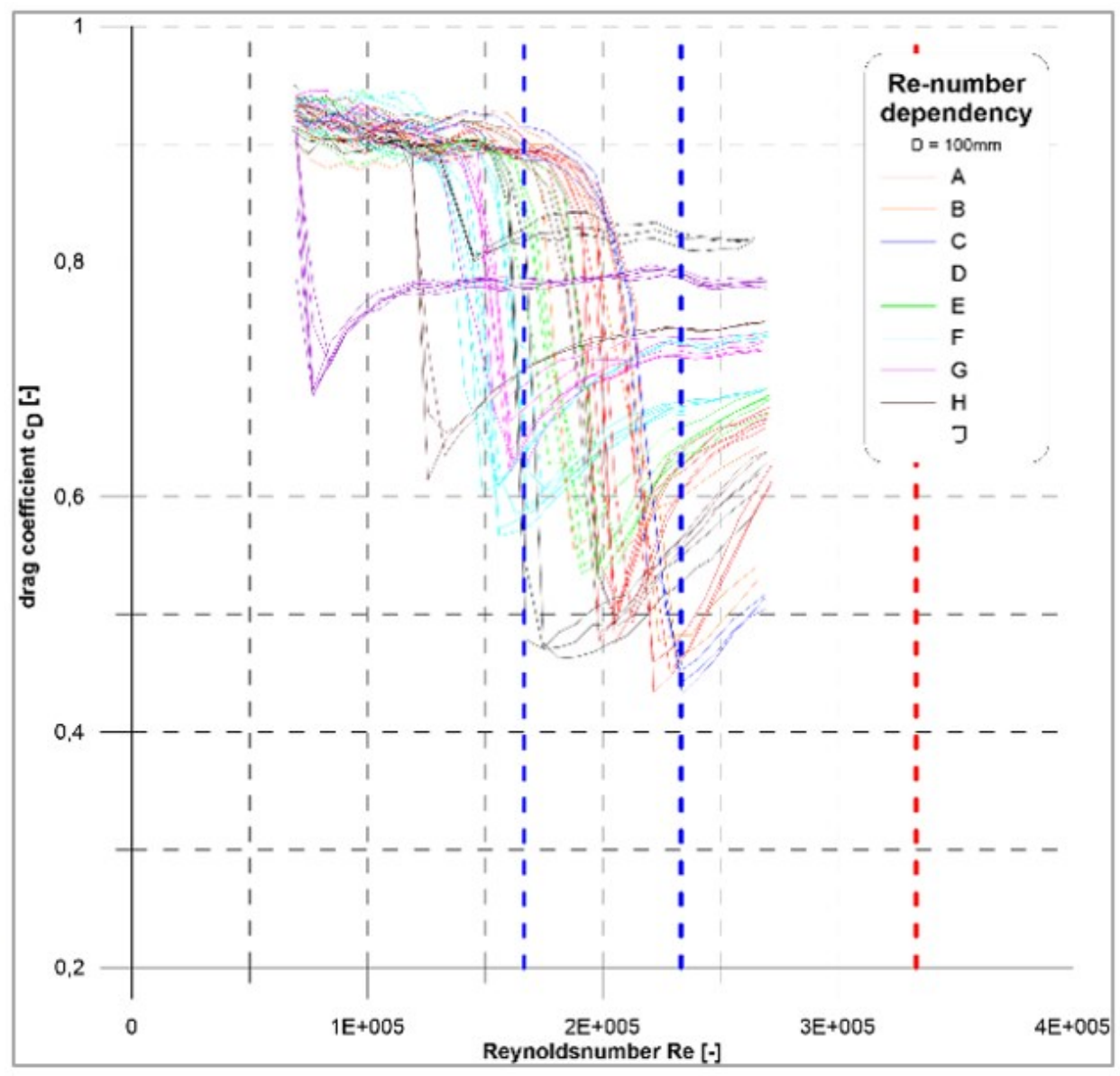

Fig. 2 Summary of drag coefficients behavior, measured for different textile materials covering rigid cylinders during the last years at the wind tunnel of TU Dresden.

Most related published work regarding high-tech fabrics can be found in the sports field for cross-country skiing competition [10]. Cylinders with diameters of 11 and $16 \mathrm{~cm}$ are used to simulate the human body for velocities from 0 to $18 \mathrm{~m} / \mathrm{s}^{2}$ and fabric strains from 0 to $65 \%$. The results show that "no clear correlation was found between air permeability and drag force, suggesting that surface deformation due to strain plays a major role compared to air permeability" [10]. In another paper [11], a small dependence of the flow transition on air permeability was found. However, the authors suggest that the low dependence is related to a limited effect of sportswear on aerodynamic performance. Chowdhury et al. [12] concluded in their study that proper selection of textiles for athletes is of paramount importance to achieve aerodynamic benefits and the surface morphology plays a key role in reducing drag and lift. All of these studies are conducted for a wide range of body types and surfaces, but all reported work is done with rigid, foiled or coated bodies. The aim of this work was to make a first preliminary evaluation of the influence of the body elasticity and the wrapped textile on the drag force. 


\section{Test environment}

\subsection{Wind Tunnel}

Figure 3 shows a sketch of the wind tunnel facility with its dimensions and identifies essential wind tunnel sections. The wind tunnel measuring jet has a special quality with respect to the homogeneity of the velocity over the jet cross section and the low turbulence characteristics. To improve the jet quality and stability in the open measuring section, a SEIFFERTH vane is installed in the nozzle exit plane. The outlet diameter of the wind tunnel nozzle is $3 \mathrm{~m}$.

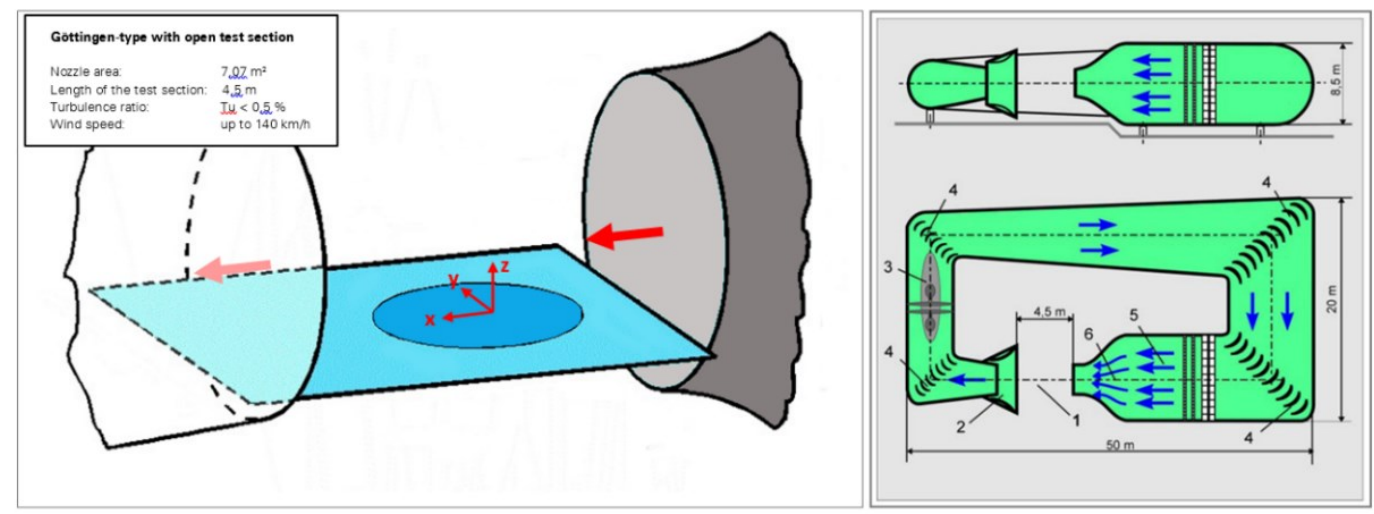

Fig. 3 Low-speed wind-tunnel Technische Universität Dresden, Chair of Flight Mechanics and Control.

\subsection{Probes}

The human body can be represented as a combination of several different geometric elements, such as cylinders.

For the current study, a standard rigid cylinder with a diameter of 0.1 meter and a soft-body cylinder with the same geometry were used. The soft-body cylinder was prepared with a $20 \mathrm{~mm}$ gelatin layer (Carl Roth $\mathrm{GmbH}+$ Co. KG, Germany). This gelatin is also used in ballistic experiments [13], [14] to represent human body deformation. According to the manufacturer, gel strength ranges from 230-250 Bloom, particle size $20-30$ mesh, protein $83-91 \%$, water $<15 \%$, ash $<2 \%$, peroxides $<0.001 \%$ and sulfur dioxide $<0.001 \%$, made from pig skin. The soft cylinder had a reinforced center support that mimicked human bone and was used to connect to the force measurement system. The complete system was placed in a wind tunnel (Fig. 4).

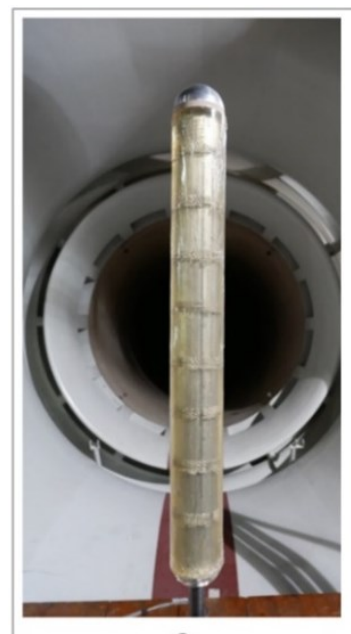

a

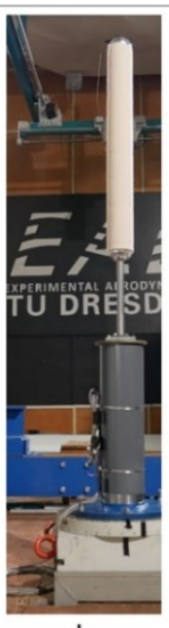

b

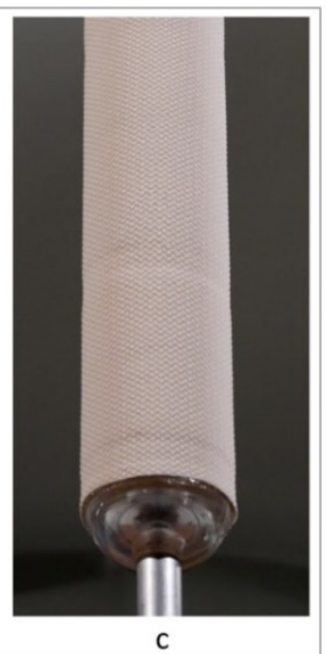

C

Fig. 4 Testing equipment for measurement of the drag coefficient at different Reynolds numbers in a wind tunnel: a) soft-body cylinder, b) with textile cover over the gelatin layer, c) close view of the cylinder with the textile. 
Avoiding differences due to production parameters (temperature, days after production) and inhomogeneities of the gelatin layer on the soft-body cylinder, the textile covering was placed over the cylinder with an additional foil for the current investigation.

For a basic comparison of the boundary layers around different textile materials, the rigid cylinder test is sufficient. This test allows a comparison of the different textile materials placed over the cylinder and their influence on the drag forces without disturbing the complex body geometries. In all these analyses, only the drag forces at the same Reynolds numbers may be compared, since only at the same number the processes are aerodynamically identical. The setup used in the case study was applied for Reynolds numbers between $5 \times 10^{4}$ and $1 \times 10^{6}$. This is the common range for athletes in the areas of arm, leg and chest at common speeds.

For this study, four of the textiles $(B, F, G, J)$ already documented were selected and one new textiles (K) concerning the development of the fabrics (cf. Table 1). The test was performed:

- with rigid cylinder (metal),

- with rigid cylinder (metal) covered with textiles,

- with soft-body cylinder with the same outer diameter, but with $20 \mathrm{~mm}$ gelatin (in the current case additionally covered with thin foil and textiles.

Table 1. Textile materials

\begin{tabular}{|c|c|c|c|c|c|c|c|}
\hline ID & Designation & Category & Type of Textile & Material & $\begin{array}{c}\text { Areal weight } \\
\left(\mathrm{g} / \mathrm{m}^{2}\right)\end{array}$ & $\begin{array}{c}\text { Thickness } \\
\text { (mm) }\end{array}$ & Picture \\
\hline B & $\begin{array}{l}\text { Nubbed, weft } \\
\text { direction }\end{array}$ & Cycling & Knitted fabric & $\begin{array}{l}70 \% \text { PA, } \\
30 \% \text { EA }\end{array}$ & 280 & 1.27 & \\
\hline $\mathbf{F}$ & 51460 & Bodyflight & $\begin{array}{l}\text { Woven fabric / } \\
\text { plain weave }\end{array}$ & $100 \% \mathrm{PA}$ & 285 & 0.74 & \\
\hline G & 50060 & Bodyflight & $\begin{array}{l}\text { Woven fabric / } \\
\text { Jacquard }\end{array}$ & $100 \% \mathrm{PA}$ & 290 & 0.65 & \\
\hline J & $\begin{array}{l}\text { Wing } \\
\text { membrane }\end{array}$ & Bodyflight & $\begin{array}{l}\text { Woven fabric / } \\
\text { plain weave }\end{array}$ & $100 \%$ PA & 120 & 0.15 & \\
\hline K & $\begin{array}{c}\text { Lace } 1, \\
\text { warp directio } \\
n\end{array}$ & Cycling & Knitted fabric & $\begin{array}{l}84 \% \mathrm{PA}, \\
16 \% \mathrm{EA}\end{array}$ & 159 & 0.81 & \\
\hline
\end{tabular}

\section{Results}

The following are the results of the cylinders without textiles and afterwards with selected textiles.

Figure 5 visualizes the results for the drag coefficient of the rigid cylinder (metal), the soft cylinder and the foil-stabilized gel cylinder. The figure shows variations of the drag coefficient between 0.92 and 1.08 at different Reynolds numbers. In addition to the quasi-constant curve, differences in the magnitude 
between the individual curves can be seen. While the Reynolds number increases, the gel deforms and the changed shape leads to changes in the drag force. The foil has a different surface and in this way influences the airflow, but it additionally fixed or stabilized the gelatin layer and in this way also influences the drag.

If we look at the results of the measurements with the textiles below, three cases can be observed. First the influence in a positive way - aerodynamic drag is lowered and the sphere of influence is shifted in favor of. Second there are no significant changes. Third the influence in a negative way - aerodynamic drag increases and the sphere of influence does not shift in favor of.

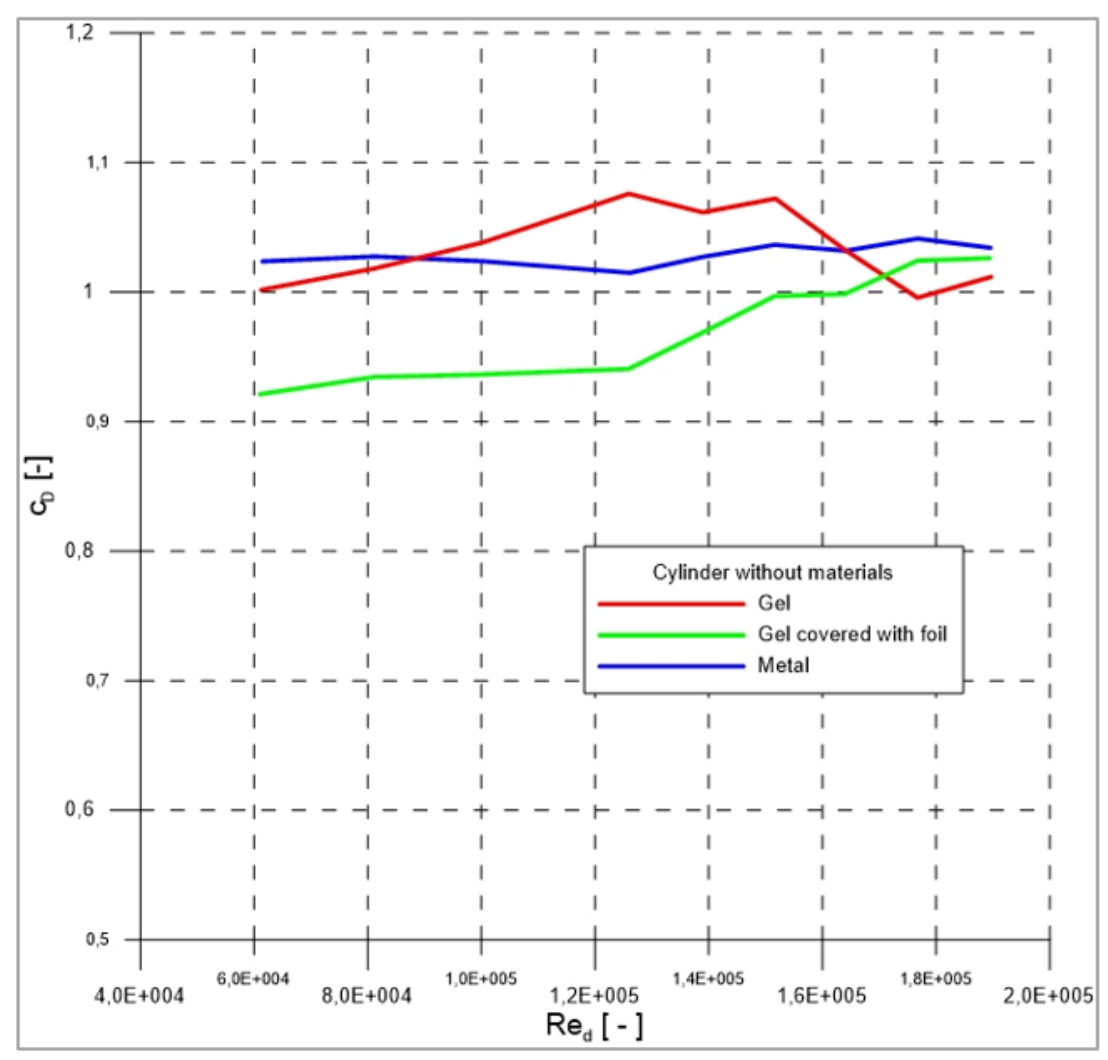

Fig. 5 Drag coefficient for cylinder with gel with and without covering foil and the rigid cylinder (metal), all without textile covering.

\subsection{First case: materials $\mathbf{G} \& \mathrm{~K}$}

The curves in Figure 6 show the difference of the rigid and the soft-body cylinder for the investigated textiles. The measurements with material $\mathrm{G}$ show an earlier drop in the drag coefficient at the soft-body cylinder. This means that lower drag can already be achieved at lower speeds. For example, to maintain a similarly low drag coefficient of 0.8 for a diameter of $0.1 \mathrm{~m}$, a $15 \%$ lower speed is required. No statement can be made about the difference in the drag minimum. Material K shows a similar tendency. Here, there is even a reduction in the drag coefficient minimum of approximately $8 \%$ visible, compared to the rigid cylinder. 


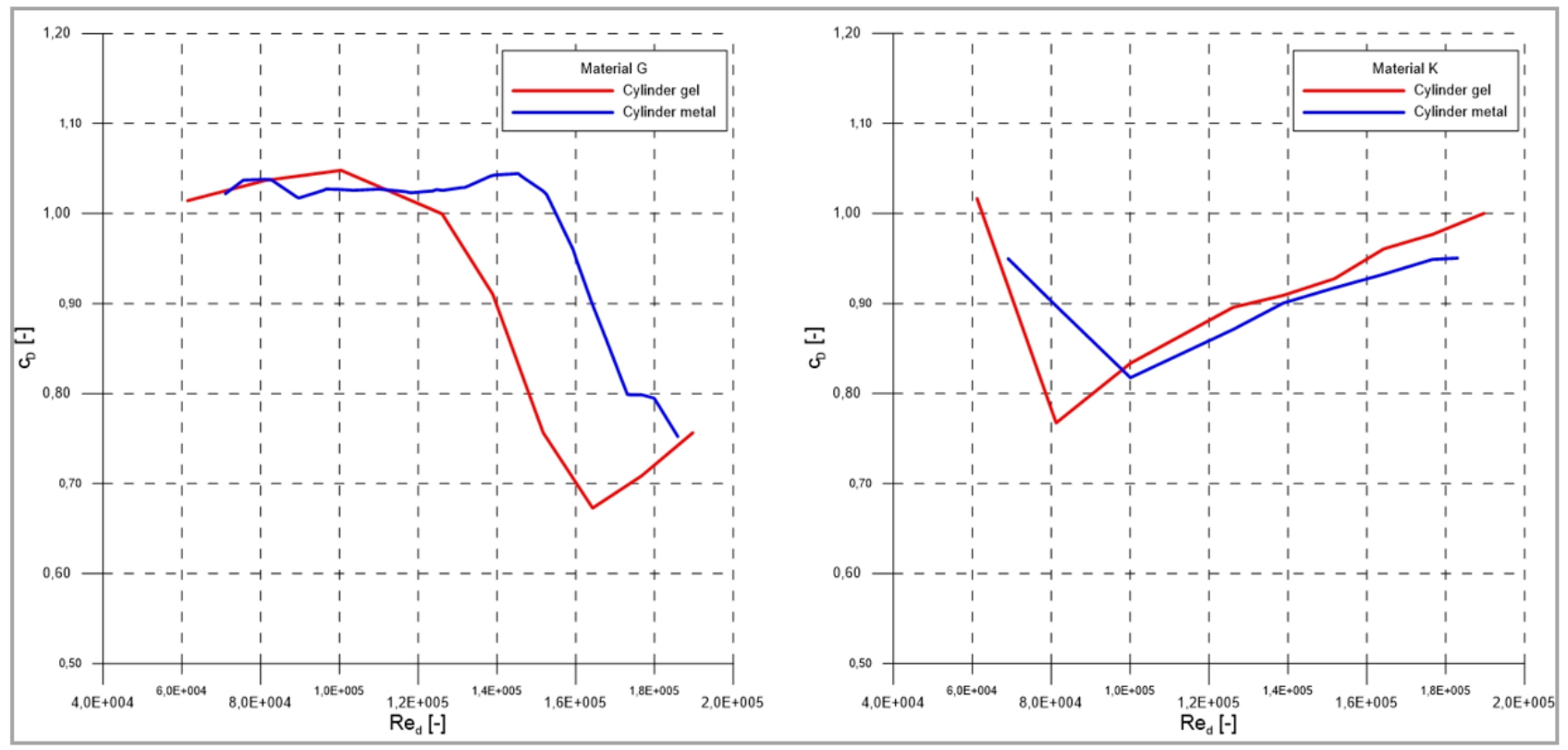

Fig. 6 Drag coefficient of soft-body cylinder with foil covered by two materials ( $G$ and $K$ ) and the rigid cylinder (metal).

\subsection{Second case: material J}

This case shows that it is primarily the fabric that determines the characteristic. In the investigated Reynolds number range (subcritical), the drag coefficient remains approximately constant (Fig. 7). The soft cylinder therefore has no influence.

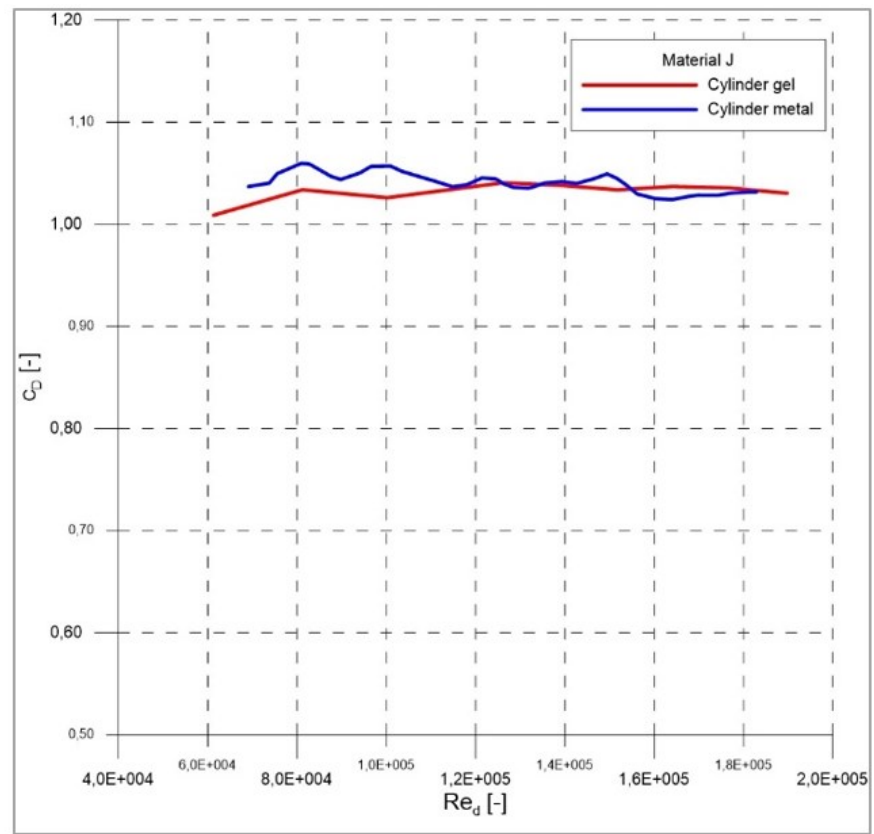

Fig. 7 Drag coefficient of soft-body cylinder with foil covered by material (J) and the rigid cylinder (metal).

\subsection{Third case: materials B \& F}

The measurements with materials $B$ and $F$ indicate an influence of the soft cylinder (Fig. 8). Material B loses quantitatively over the entire investigated area about up to $2 \%$ in the drag coefficient. With material 
$\mathrm{F}$, a shift of the critical point by about $7 \%$ to higher Re numbers can be seen. Finally, in all three cases, the influence of the soft cylinder on the drag coefficient depends on the textile material.

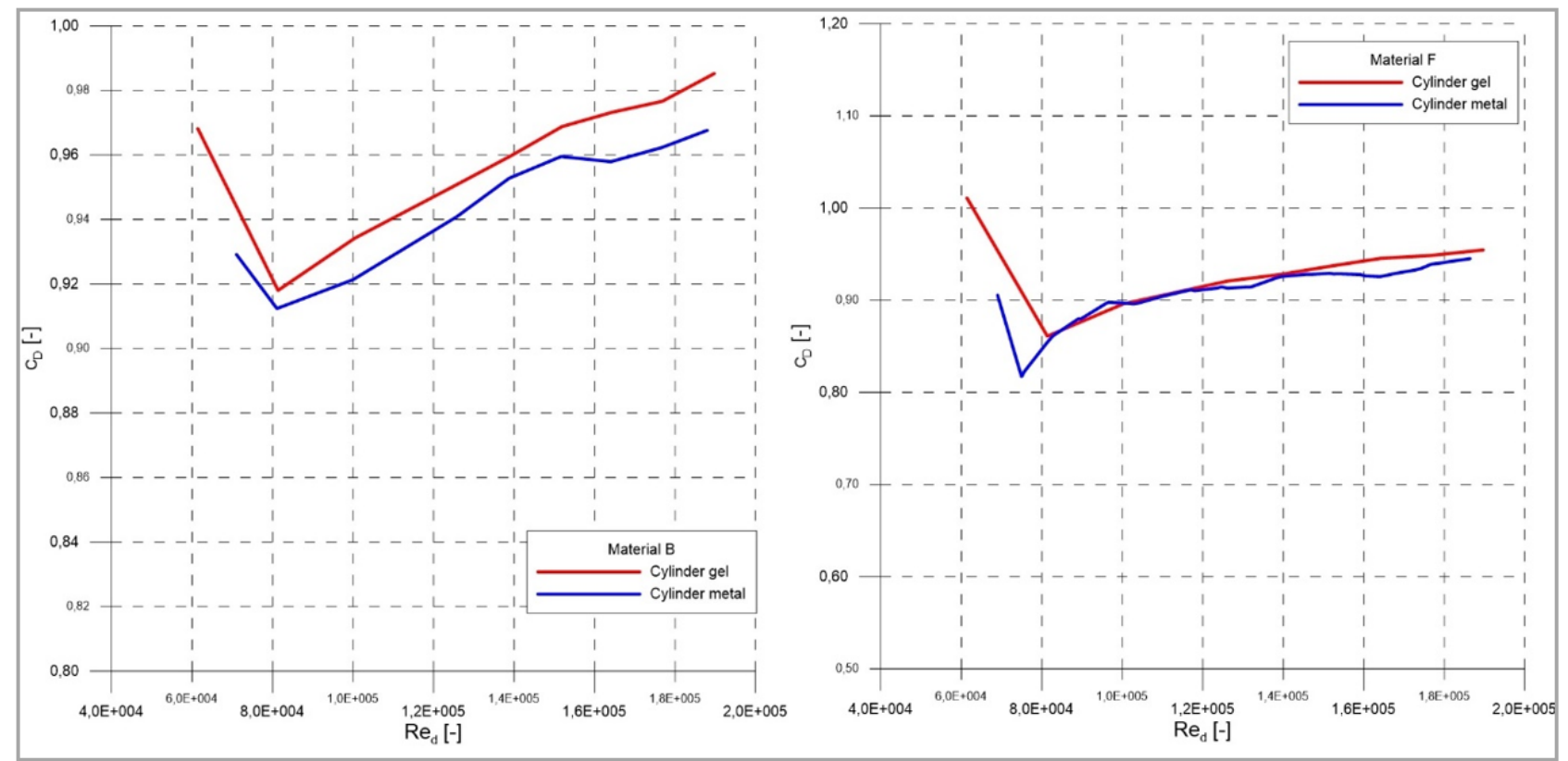

Fig. 8 Drag coefficient of soft-body cylinder with foil covered by two materials $(B, F)$ and a rigid cylinder (metal).

\section{Conclusions}

This preliminary investigation confirmed previous findings that the textile surfaces significantly affect the nature of airflow around the cylinder and thus the drag coefficient of the measuring probe. The aim of the current study was to analyze the influence of body elasticity (or stiffness) on the drag coefficient. The use of a softer deformable gelatin layer over the cylinder provides a different surface and additional deformation under the influence of the airflow, which changes the drag coefficient. The changes have a different character in the case of covering the gelatin cylinder with thin foil or without. The measurements with textiles indicate both positive and negative influence on the aerodynamic drag. This means the results on using the soft-body cylinder depend on the covered textile material. These preliminary results show that the interaction between airflow, textile and soft-body cylinder has a significant influence on the drag coefficient (up to 15\%). However, due to the limited number of experiments, no trend of these changes could be observed. The conclusion of this study is a deeper systematic investigation of the individual parameters and their joint interactions in order to provide a deeper fundamental understanding in the future and to establish new bases for the optimization of wind-interacting clothing.

\section{References}

[1] Frederich, O. Numerische Simulation und Analyse turbulenter Strömungen am Beispiel der Umströmung eines Zylinderstumpfes mit Endscheibe. Zugl.: Berlin, Techn. Univ. Dissertation thesis, 2010, Univ.-Verl. der TU, Berlin, Germany.

[2] Hucho, W.-H. Aerodynamik der stumpfen Körper. Physikalische Grundlagen und Anwendungen in der Praxis; mit 56 Tabellen. 2012. Vieweg+Teubner Verlag, Wiesbaden, Germany.

[3] Moria, H.; Chowdhury, H.; Aldawi, F.; Alam, F. A cylindrical methodology for the study of fabric aerodynamics. Procedia Engineering 2013, 56, 297-302. DOI: https://doi.org/10.1016/j.proeng.2013.03.121.

[4] Neumann, D. Widerstandsminderung durch Rillenstrukturen auf der Oberfläche eines längs angeströmten Kreiszylinders. Mitteilungen aus dem Max-Planck-Institut für Strömungsforschung 1989, 92.

[5] Guttag, M.; Reis, P. M. Active aerodynamic drag reduction on morphable cylinders. Phys. Rev. Fluids 2017, 2 , 123903. DOI: https://doi.org/10.1103/PhysRevFluids.2.123903.

[6] Kunze, S. Untersuchungen zur Strömungs- Struktur Interaktion an dynamisch bewegten, flexiblen Oberflächen. Dissertation thesis, 2011, Technische Universität Bergakademie Freiberg, Germany. 
[7] Mack, C.; Smart, E. J. L. Measurements of the air-drag of textile threads. Journal of the Textile Institute Transactions 1954, 45, 4, T348-T362. DOI: https://doi.org/10.1080/19447025408662656.

[8] Tang, Z.-X.; Wang, X.; Wang, L.; Fraser, W. B. The effect of yarn hairiness on air drag in ring spinning. Textile Research Journal 2006, 76, 7, 559-566. DOI: https://doi.org/10.1177/0040517506064472.

[9] Chen, C. H.; White, J. L.; Spruiell, J. E.; Goswami, B. C. Dynamics, air drag, and orientation development in the spunbonding process for nonwoven fabrics. Textile Research Journal 1983, 53, 1, 44.51. DOI: https://doi.org/10.1177/004051758305300108.

[10] Oggiano, L.; Roar, S. L.; Morten, B. L.; Brian, H. Air permeability and drag crisis on high tech fabrics for cross country ski competitions. Procedia Engineering 2012, 34, 15-19. DOI: https://doi.org/10.1016/j.proeng.2012.04.004

[11]Bardal, L. M.; Reid, R. The effect of textile air permeability on the drag of high-speed winter sports apparel. Sports Eng. 2014, 17, 2, 83-88. DOI: https://doi.org/10.1007/s12283-013-0134-y.

[12] Chowdhury, H.; Alam, F.; Subic, A. Aerodynamic performance evaluation of sports textile. Procedia Engineering 2010, 2, 2, 2517-2522. DOI: https://doi.org/10.1016/j.proeng.2010.04.025.

[13] Fackler, M. L.; Malinowski, J. A. Ordnance gelatin for ballistic studies. Detrimental effect of excess heat used in gelatin preparation. The American Journal of Forensic Medicine and Pathology 1988, 9, 3, 218-219.

[14] Maiden, N. R.; Fisk, W.; Wachsberger, C.; and Byard, R. W. Ballistics ordnance gelatine - How different concentrations, temperatures and curing times affect calibration results. Journal of Forensic and Legal Medicine 2015, 34, 145-150. DOI: https://doi.org/10.1016/j.jflm.2015.05.019. 